\title{
Can a Summer Hike Cause Surprise Fall for Mortgage Rates?
}

\author{
Kristie M. Engemann and Michael T. Owyang
}

A fter persistent decreases in the federal funds rate target for the past four years, the Federal Open Market Committee (FOMC) increased the target by 25 basis points at their June meeting. One might assume that raising rates dampens demand in interest-sensitive markets, such as housing, but data from the Mortgage Bankers Association show the opposite can occur. In the week following the FOMC's decision, the total number of mortgage applications (the Mortgage Composite Index) increased by nearly 20 percent on a seasonally adjusted basis as the long-term (15-year and 30 -year) fixed rates fell by over 20 basis points. At the time this cover page was written, mortgage rates continue to be lower and mortgage demand higher than before the decision to raise the federal funds rate.

A funds rate increase can affect the market for mortgages in a number of ways, and some examples follow. Mortgages are long-term loans, meaning that the mortgage rate depends on both current short-term interest rates, e.g., the federal funds rate, and expected future short rates, which partly depend on inflation expectations. Therefore, one effect is that, other things equal, an increase in the funds rate causes long rates to rise. Another effect is that markets might expect future inflation to fall when the funds rate increases because this eases upward pressure on inflation. Thus, when the funds rate rises, long-term mortgage rates might remain unchanged or even fall. Additionally, raising the funds rate has an intertemporal substitution effect, whereby an increase now might signal that further increases are impending. As a result, borrowers may decide to apply for mortgages now before rates become higher. This, in turn, raises short-run mortgage demand. Assuming expected inflation does in fact fall, the latter two effects on mortgage demand counterbalance the first.

As the chart shows, the funds rate has remained between 1.00 and 1.75 percent since November 2002, with two long periods of almost no change; however, within those two periods, the 30-year fixed rate moved continually, due partially to fluctuating inflation expec- tations. Mortgage demand also fluctuated greatly during this time. For the two funds rate decreases that are shown, the long rate increased, suggesting that the increase in expected inflation swamped the effect of the decline in current short rates. Concurrently, mortgage demand fell in these episodes, perhaps because of the combination of the indirect effect of higher inflation expectations and the lack of a sense of urgency to apply for mortgages. Since June of this year, when the funds rate increased, the 30-year mortgage rate has fallen, and mortgage demand has risen slightly, possibly reflecting both lower rates and homeowners' urgency to secure loans before an anticipated series of funds rate target increases by the FOMC.

Despite the recent increase in the federal funds rate target, there was not an immediate increase in long-term rates and lower mortgage demand. Thus, it is incorrect to assume that monetary policy tightenings will always curtail housing in the short run. Nevertheless, coming weeks may yet see a decline in mortgage applications, as many borrowers may have moved their purchase and refinancing decisions forward.

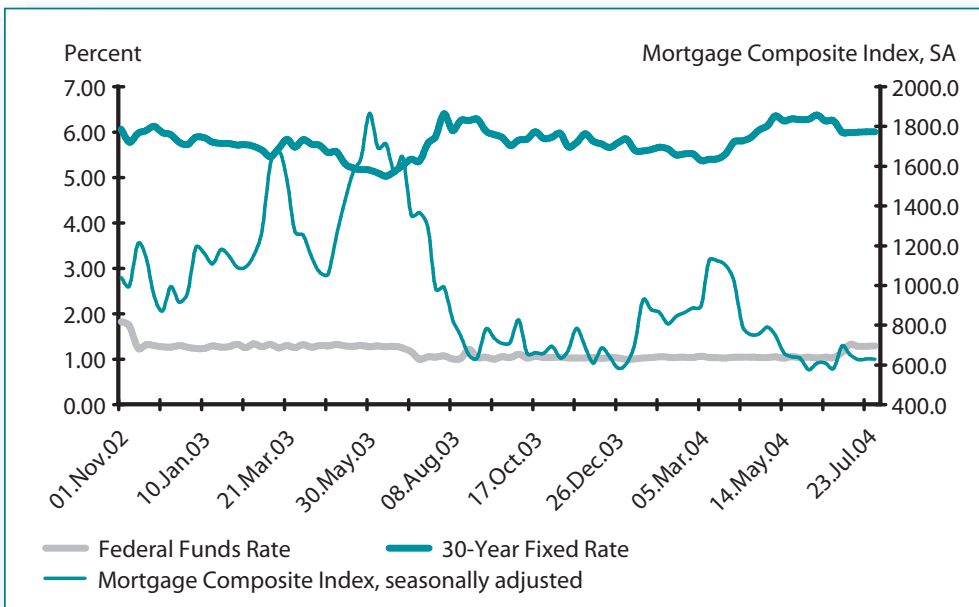

NOTE: For the mortgage index, the week ending March 16, $1990=100$. SOURCE: Mortgage Bankers Association and the Federal Reserve Board. 